\title{
New Micromechanical Model for Predicting Biaxial Tensile Moduli of Plain Weave Fabric Composites
}

\section{J B Bai, J J Xiong*, Q Wang}

School of Transportation Science and Engineering, Beihang University, Beijing, 100191, People's Republic of China (*, corresponding author: jjxiong@buaa.edu.cn)

\begin{abstract}
This paper addresses a new micromechanical model to predict biaxial tensile moduli of plain weave fabric (PWF) composites by considering the interaction between the orthogonal interlacing strands. The two orthogonal yarns in micromechanical unit cell (UC) were idealized as the curved beams with a path depicted by using sinusoidal shape functions. The biaxial tensile moduli of PWF composites were derived by means of the minimum total complementary potential energy principle founded on micromechanics. The biaxial tensile tests were respectively conducted on the RTM-made EW220/5284 PWF composites at five biaxial loading ratios of $0,1,2,3$ and $\infty$ to validate the new model. The predictions from the new model were compared with experimental data and good correlation was achieved between the predictions and actual experiments, demonstrating the practical and effective use of the proposed model. Using the new model, the biaxial tensile moduli of plain weave fabric (PWF) composites could be predicted based only on the properties of basic woven fabric.
\end{abstract}

Key words: textile composite; biaxial tensile; modulus; plain weave fabric (PWF)

\section{NOMENCLATURE}

A cross-section area of yarn, $\mathrm{mm}^{2}$

$A_{1} \quad$ cross-section area of warp yarn, $\mathrm{mm}^{2}$ 
$A_{2} \quad$ cross-section area of weft yarn, $\mathrm{mm}^{2}$

$C_{i} \quad$ transformation variable

$D_{i} \quad$ transformation variable

E elastic modulus of yarn in longitudinal direction, $\mathrm{MPa}$

$E_{1} \quad$ warp elastic modulus of plain weave fabric composites under biaxial loadings, MPa

$E_{2} \quad$ weft elastic modulus of plain weave fabric composites under biaxial loadings, MPa

$E_{f} \quad$ elastic modulus of fibre, $\mathrm{MPa}$

$E_{m} \quad$ elastic modulus of resin, $\mathrm{MPa}$

$E_{f 1} \quad$ warp elastic modulus of plain weave fabric under biaxial loadings, MPa

$E_{f 2} \quad$ weft elastic modulus of plain weave fabric under biaxial loadings, $\mathrm{MPa}$

F internal force of yarn along axial direction, $\mathrm{N}$

$h \quad$ thickness of yarn, $\mathrm{mm}$

$h_{1} \quad$ thickness of warp yarn, $\mathrm{mm}$

$h_{2} \quad$ thickness of warp yarn, $\mathrm{mm}$

$H \quad$ thickness of ply, $\mathrm{mm}$

I inertia moment of yarn along transverse direction, $\mathrm{mm}^{4}$

$I_{1} \quad$ inertia moment of warp yarn along transverse direction, $\mathrm{mm}^{4}$

$I_{2} \quad$ inertia moment of weft yarn along transverse direction, $\mathrm{mm}^{4}$

$L \quad$ quarter undulation length of yarn, $\mathrm{mm}$

$L_{1} \quad$ quarter undulation length of warp yarn, $\mathrm{mm}$

$L_{2} \quad$ quarter undulation length of weft yarn, $\mathrm{mm}$

M internal bending moment, $\mathrm{N} \cdot \mathrm{mm}$

$M_{1} \quad$ internal bending moment on warp yarn, $\mathrm{N} \cdot \mathrm{mm}$ 


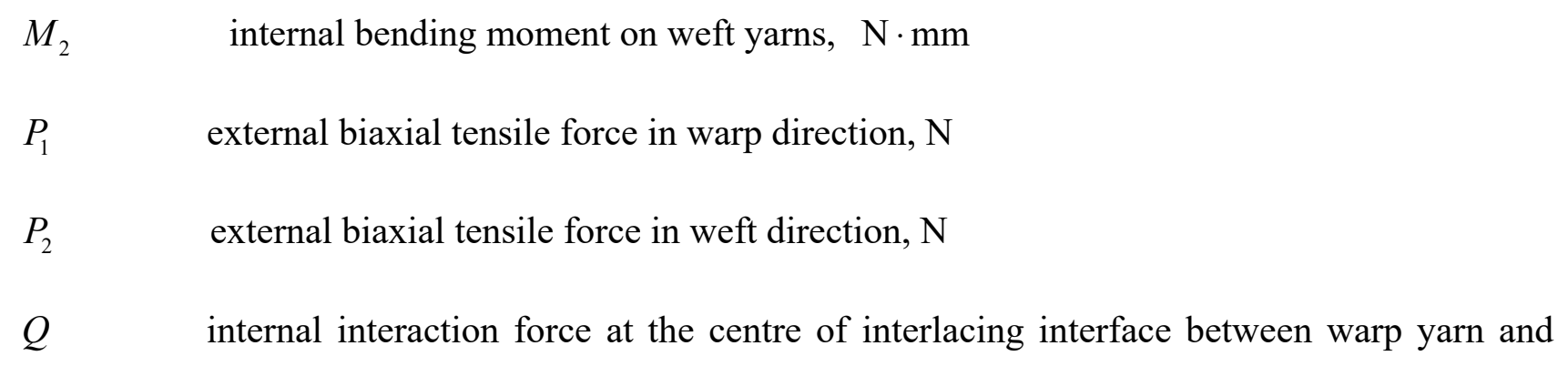

weft yarn along through-thickness direction, $\mathrm{N}$

$U_{1}^{*} \quad$ complementary potential energy of warp yarn in the UC

$U_{2}^{*} \quad$ complementary potential energy of weft yarn in the UC

$V_{f} \quad$ fibre volume fraction in yarn

$V_{f 1} \quad$ fibre volume fraction in the UC

$V_{f 2} \quad$ yarn volume fraction in the UC

w width of yarn, $\mathrm{mm}$

$w_{1} \quad$ width of warp yarn, $\mathrm{mm}$

$w_{2} \quad$ width of weft yarn, $\mathrm{mm}$

$\Pi^{*} \quad$ total complementary potential energy of the UC

$\lambda \quad$ loading ratio of tensile force in warp direction to tensile force in weft direction

$\theta \quad$ off-axial angle of yarn, rad

$\delta_{P_{1}} \quad$ relative shift of $\mathrm{UC}$ in the direction of external warp force $P_{1}, \mathrm{~mm}$

$\delta_{P_{2}} \quad$ relative shift of $\mathrm{UC}$ in the direction of external weft force $P_{2}, \mathrm{~mm}$

FE finite element

UC unit cell

PWF plain weave fabric 


\section{INTRODUCTION}

Textile composites are commonly used in engineering structures (especially in aerospace structures) owing to the superior specific stiffness and strength as well as excellent damage resistance and processing property ${ }^{[1-6]}$. Recently, with potential for the wider applications of plain weave fabric (PWF) composite structures, there is growing interest in assessing mechanical properties and failure mechanism for PWF composites using experimental, theoretical and numerical methods ${ }^{[7-13]}$. Koohbor et al. ${ }^{[14]}$ conducted an experimental investigation to examine the multi-scale deformation and failure mechanisms of PWF composites under uniaxial tension using digital image correlation. The full-field displacement and strain localization were effectively captured and found that the mechanical response and failure modes of PWF composites distinctly depended on the off-axial degree of loading axis to principal axis. Koohbor et al. ${ }^{[15]}$ further developed a systematic experimental-based method to determine the local deformation response and the length scales of the unit cell (UC) in PWF composites under on-axis and off-axis tensile loadings. It was found that the smallest UC sizes were depended on both strain and angle and the largest UC dimension was a unique, strain and orientation insensitive UC size for PWF composites. Boufaida et al. ${ }^{[16]}$ experimentally investigated the damage development of PWF composites with \pm 45 off-axial degree subjected to uniaxial tensile loading using digital image correlation and X-ray microtomography. The experiments showed that the PWF composites exhibited linear viscoelastic behaviour until a given stress threshold above which the damage initiated and propagated in the materials.

Because of the resource constraints, various analytical models have been presented to evaluate mechanical properties of PWF composites. Scida et al. ${ }^{[17]}$ developed an analytical model to predict 3D elastic and failure properties of PWF composites based on the classical thin laminate theory. Stiffness and strength were computed and compared with the experimental data and with the 
predictions from other micromechanical models. Jiang et al. ${ }^{[18]}$ presented a stress-strain averaging procedure for local/global analysis of PWF composites. The unit cell and subcells were used to obtain the constitutive equations and the effective stress-strain relations. The predictions were in a good agreement with FE results. Naik et al. ${ }^{[19]}$ proposed an analytical model to predict the compressive behaviour of PWF composites under on-axis uniaxial loading based on curved elastic beams foundation. Effect of fabric geometry on the compressive behaviour of PWF composites was investigated. The predictions agreed well with experimental data. Wang et al. ${ }^{[20,21]}$ conducted a theoretical investigation to characterize the influences of stochastic feature parameters of yarn on elastic properties of PWF composites. Volume averaging method was adopted to determine the elastic properties of PWF composites. It was found that the real stochastic physical phenomena of yarn can influence all of the elastic constants of PWF composites. In recent years, the FE method has been commonly used in assessing mechanical properties and failure mechanism of PWF composites. Karkkainen et al. ${ }^{[22]}$ implemented a micromechanical analysis based on the FE analysis of the UC to investigate stress gradient effects and failure initiation of PWF composites and found that transverse failure of the yarn was the dominant mode of initial failure. Barbero et al. ${ }^{[23]}$ developed FE models to determine mechanical properties of PWF composites. The geometric models needed for FE discretization of PWF composites were obtained from actual measurements of yarn geometry. Predictions had a good correlation with experiments. Bakar et al. ${ }^{[24]}$ numerically determined geometric characteristics and elastic properties of PWF composites using FE models based on UC with periodic boundary conditions. An evolutionary algorithm was employed to optimize the elastic properties of PWF composites. However, in order to produce FE models, straight inclined segments or continuous mathematical functions have been used to depict in more detail the idealized PWF geometry including yarn path and cross-sectional shape. The one draw 
back of FE models is their intensity and complexity. It is obvious that the analytical methods still have consistently received interests to evaluate mechanical properties of textile composites and there is a need for a more practical and expedient analytical model for structural applications.

Although a large amount of research has been conducted on the mechanical properties and failure mechanism of PWF composites under uniaxial loading, the biaxial tensile moduli of PWF composites have been scarcely reported and the related mechanism has not been systematically studied. Hence, a need exists for fully understanding the effect of loading ratios on the mechanical properties of PWF composites under biaxial loadings; furthermore, a technique for assessing the biaxial tensile moduli of PWF composites in engineering design is desirable, which is the focus of this paper.

\section{GEOMETRICAL MODEL FOR PWF COMPOSITES}

The PWF composites are formed by orthogonal interlacing yarns in the directions of $0^{\circ}$ and $90^{\circ}$ (shown in Figure 1). The directions of $0^{\circ}$ and $90^{\circ}$ correspond to the warp and weft yarns in the PWF composites. The crimp or undulation of yarns due to the orthogonal interlacing between biaxial yarns has a significant influence on mechanical properties and strengths of PWF composites. The periodicity of the repeating pattern in PWFs can be characterized by the UC (unit cell). The UC in yarn interlacing pattern for the PWFs is indicated in Figure 1. In order to establish analytical models of the UC, fundamental assumptions made in this paper are as follows:

(1) The cross-section of yarns is regarded as the combination of a flat rectangle and two semicircles with the width of $w$ and the thickness of $h$ (shown in Figure 2).

(2) The yarns are idealized as the curved beams with an undulated neutral axis depicted by using a smooth and continuous sinusoidal curve function (shown in Figure 3). 
Figure 4 illustrates the definitions of three directions of $\mathrm{x} \mathrm{y}$ and $\mathrm{z}$ axis in local coordinate system. The coordinate axes $\mathrm{x} y$ and $\mathrm{z}$ respectively denote the longitudinal, transverse and through-thickness directions of the yarns to ensure the fibres with correct $3 \mathrm{D}$ orientation, i.e., to keep three directions of $\mathrm{x}, \mathrm{y}$ and $\mathrm{z}$ axis in local coordinate system consistent with three normal stresses.

From Assumption (1) and Figure 2, the area and inertia moments of idealized cross-section of biaxial yarns are respectively

$$
\begin{gathered}
A=\frac{\pi h^{2}}{4}+h(w-h) \\
I=\frac{1}{64} \pi h^{4}+\frac{1}{12} h^{3}(w-h)
\end{gathered}
$$

From Assumption (2) and Figure 4, the undulated neutral axis of biaxial yarns can be expressed by a sinusoidal function.

$$
z=\frac{h}{2} \sin \frac{\pi x}{2 L}
$$

where $h$ is the thickness of yarn and $L$ is the quarter undulation length of yarn.

From Figure 4 and Equation (3), for a differential segment $d x$ on a warp or weft yarn, the tangent of off-axial angle can be obtained as follows.

$$
\tan \theta=\frac{d z}{d x}=\frac{\pi h}{4 L} \cos \frac{\pi x}{2 L}
$$

The yarn volume fraction in the UC can be shown as

$$
V_{f 2}=\left(4 L_{1} L_{2} H\right)^{-1}\left(2 \int_{0}^{L_{1}} A_{1} \sqrt{1+\left(\frac{\pi h_{1}}{4 L_{1}} \cos \frac{\pi x}{2 L_{1}}\right)^{2}} d x+2 \int_{0}^{L_{2}} A_{2} \sqrt{1+\left(\frac{\pi h_{2}}{4 L_{2}} \cos \frac{\pi x}{2 L_{2}}\right)^{2}} d x\right)
$$

where $H$ is the ply thickness of the PWF composites.

Thus, the fibre volume fraction in the yarn becomes

$$
V_{f}=V_{f 1} / V_{f 2}
$$

where $V_{f 1}$ is the fibre volume fraction in the UC. 


\section{ANALYTICAL SOLUTION FOR BIAXIAL TENSILE MODULI}

For biaxial tensile loadings (shown in Figures 3 and 4), the loading ratio of the warp tensile force to the weft tensile force is defined as

$$
\lambda=\frac{P_{1}}{P_{2}}
$$

where $P_{1}$ and $P_{2}$ are respectively the warp and weft tensile forces

The internal force and bending moment on any cross-section in the warp and weft yarns are respectively

$$
\begin{gathered}
F(x)=P_{1} \cos \theta+\frac{Q}{2} \sin \theta \\
M(x)=M_{1}+P_{1} z-\frac{Q}{2} x \\
F(x)=P_{2} \cos \theta+\frac{Q}{2} \sin \theta \\
M(x)=M_{2}+P_{2} z-\frac{Q}{2} x
\end{gathered}
$$

It is clear that there are three undetermined force and moments of $M_{1}, M_{2}$ and $Q$ in Equations (8) to (11). Using the principle of minimum total complementary potential energy, it is possible to determine these undetermined force and moments. The complementary potential energies in warp and weft yarns in the UC are respectively

$$
\begin{aligned}
& U_{1}^{*}=\frac{1}{E I_{1}} \int_{0}^{L_{1}} M^{2}(x) \sqrt{1+\left(\frac{\pi h_{1}}{4 L_{1}} \cos \frac{\pi x}{2 L_{1}}\right)^{2}} d x+\frac{1}{E A_{1}} \int_{0}^{L_{1}} F^{2}(x) \sqrt{1+\left(\frac{\pi h_{1}}{4 L_{1}} \cos \frac{\pi x}{2 L_{1}}\right)^{2}} d x \\
& U_{2}^{*}=\frac{1}{E I_{2}} \int_{0}^{L_{2}} M^{2}(x) \sqrt{1+\left(\frac{\pi h_{2}}{4 L_{2}} \cos \frac{\pi x}{2 L_{2}}\right)^{2}} d x+\frac{1}{E A_{2}} \int_{0}^{L_{2}} F^{2}(x) \sqrt{1+\left(\frac{\pi h_{2}}{4 L_{2}} \cos \frac{\pi x}{2 L_{2}}\right)^{2}} d x
\end{aligned}
$$

where $I_{1}$ and $I_{2}$ are respectively the inertia moment of warp and weft yarns along transverse direction. $A_{1}$ and $A_{2}$ are respectively the cross-section area of warp and weft yarns. $E$ is the elastic modulus of yarn in longitudinal direction, and can be deduced as follows.

$$
E=E_{f} V_{f}+E_{m}\left(1-V_{f}\right)
$$

Substituting Equations (8) and (9) into Equation (12), and again substituting Equations (10) and (11) 
into Equation (13), it can be shown that

$$
\begin{gathered}
U_{1}^{*}=C_{1} M_{1}^{2}+\left(C_{2}+C_{7}\right) P_{1}^{2}+\left(C_{3}+C_{8}\right) Q^{2}+C_{4} M_{1} P_{1}+\left(C_{5}+C_{9}\right) P_{1} Q+C_{6} M_{1} Q \\
U_{2}^{*}=C_{10} M_{2}^{2}+\left(C_{11}+C_{16}\right) P_{2}^{2}+\left(C_{12}+C_{17}\right) Q^{2}+C_{13} M_{2} P_{2}+\left(C_{14}+C_{18}\right) P_{2} Q+C_{15} M_{2} Q
\end{gathered}
$$

where $C_{i}(i=1,2,3 \ldots \ldots 18)$ are the transformation variables, and are defined in Appendix A.

Total complementary potential energy in the UC is deduced as

$$
\begin{aligned}
\Pi^{*}=U_{1}^{*} & +U_{2}^{*}=C_{1} M_{1}^{2}+C_{10} M_{2}^{2}+\left(C_{2}+C_{7}\right) P_{1}^{2}+\left(C_{11}+C_{16}\right) P_{2}^{2}+\left(C_{3}+C_{8}+C_{12}+C_{17}\right) Q^{2} \\
& +C_{4} M_{1} P_{1}+C_{13} M_{2} P_{2}+\left(C_{5}+C_{9}\right) P_{1} Q+\left(C_{14}+C_{18}\right) P_{2} Q+C_{6} M_{1} Q+C_{15} M_{2} Q
\end{aligned}
$$

Minimizing the total complementary potential energy principle in the UC leads to

$$
\left\{\begin{array}{c}
2 C_{1} M_{1}+C_{6} Q=-C_{4} P_{1} \\
2 C_{10} M_{2}+C_{15} Q=-C_{13} P_{2} \\
C_{6} M_{1}+C_{15} M_{2}+2\left(C_{3}+C_{8}+C_{12}+C_{17}\right) Q=-\left(C_{5}+C_{9}\right) P_{1}-\left(C_{14}+C_{18}\right) P_{2}
\end{array}\right.
$$

Substituting Equation (7) into Equation (18) attains

$$
\left\{\begin{array}{c}
2 C_{1} M_{1}+C_{6} Q=-C_{4} P_{1} \\
2 C_{10} M_{2}+C_{15} Q=-\frac{C_{13}}{\lambda} P_{1} \\
C_{6} M_{1}+C_{15} M_{2}+2\left(C_{3}+C_{8}+C_{12}+C_{17}\right) Q=-\left[\left(C_{5}+C_{9}\right)+\frac{1}{\lambda}\left(C_{14}+C_{18}\right)\right] P_{1}
\end{array}\right.
$$

Solving Equation (19) by using Cramer's rule yields

$$
\begin{aligned}
& M_{1}=D_{1} P_{1} \\
& M_{2}=D_{2} P_{1} \\
& Q=D_{3} P_{1}
\end{aligned}
$$

where $D_{i} \quad(i=1,2,3)$ are the transformation variables, and are defined in Appendix B.

Again, according to the principle of minimum potential energy principle, the shifts $\delta_{P_{1}}$ and $\delta_{P_{2}}$ of the UC in the direction of external warp and weft tensile forces are respectively deduced as

$$
\delta_{P_{1}}=\frac{\partial \Pi^{*}}{\partial P_{1}}=2\left(C_{2}+C_{7}\right) P_{1}+C_{4} M_{1}+\left(C_{5}+C_{9}\right) Q
$$




$$
\delta_{P_{2}}=\frac{\partial \Pi^{*}}{\partial P_{2}}=2\left(C_{11}+C_{16}\right) P_{2}+C_{13} M_{2}+\left(C_{14}+C_{18}\right) Q
$$

Substituting Equations (20) to (22) into Equations (23) and (24), it is possible to show

$$
\begin{aligned}
& \delta_{P_{1}}=\left[2\left(C_{2}+C_{7}\right)+C_{4} D_{1}+\left(C_{5}+C_{9}\right) D_{3}\right] P_{1} \\
& \delta_{P_{2}}=\left[\frac{2}{\lambda}\left(C_{11}+C_{16}\right)+C_{13} D_{2}+\left(C_{14}+C_{18}\right) D_{3}\right] P_{1}
\end{aligned}
$$

Therefore, the warp and weft biaxial elastic moduli of PWFs are respectively

$$
\begin{gathered}
E_{f 1}=\frac{P_{1} L_{1}}{L_{2}\left(h_{1}+h_{2}\right) \delta_{P_{1}}}=\frac{L_{1}}{L_{2}\left(h_{1}+h_{2}\right)}\left[2\left(C_{2}+C_{7}\right)+C_{4} D_{1}+\left(C_{5}+C_{9}\right) D_{3}\right]^{-1} \\
E_{f 2}=\frac{P_{2} L_{2}}{L_{1}\left(h_{1}+h_{2}\right) \delta_{P_{2}}}=\frac{L_{2}}{\lambda L_{1}\left(h_{1}+h_{2}\right)}\left[\frac{2}{\lambda}\left(C_{11}+C_{16}\right)+C_{13} D_{2}+\left(C_{14}+C_{18}\right) D_{3}\right]^{-1}
\end{gathered}
$$

In lights of the well-known rule of mixtures from the moduli of PWFs and resin, the biaxial elastic moduli of PWF composites in warp and weft directions are obtained respectively

$$
\begin{aligned}
& E_{1}=E_{f 1} V_{f 2}+E_{m}\left(1-V_{f 2}\right) \\
& E_{2}=E_{f 2} V_{f 2}+E_{m}\left(1-V_{f 2}\right)
\end{aligned}
$$

Notably, if $\lambda=0$ (i.e. $P_{1}=0$ ) or $\lambda=\infty$ (i.e. $P_{2}=0$ ), then the solutions in Equations (29) and (30), are degraded into the uniaxial tensile moduli of PWF composites.

\section{COMPARISONS BETWEEN PREDICTIONS AND EXPERIMENTS}

\subsection{Biaxial tensile tests}

The test specimens were made of 2D orthogonal glass fibre/epoxy resin reinforced composites (i.e. EW220/5284 PWF composites). EW220 is a glass fibre PWF and 5284 is an epoxy resin. The fabric specifications and mechanical properties of textile composites are listed in Table 1. Figure 5 details the geometry and dimensions of cross-type specimen for biaxial tensile test. In order to conveniently measure load-strain curve under biaxial tensile loading, the diamond-shaped thinner 
area was fabricated on the central tested region of the cross-type specimen using the RTM technique. The fiber volume fraction of all specimens is 55\%. The ply thickness of EW220/5284 PWF composites is $0.167 \mathrm{~mm}$.

As shown in Figure 6, a lever-type device was used for biaxial tensile test to obtain the biaxial tensile forces on the arms of specimen at a given loading ratio, by adjusting the lever lengths. Biaxial tensile tests were conducted on a QBS-100 servo-hydraulic machine in dry state at room temperature at five biaxial loading ratios of $0,1,2,3$ and $\infty$ (shown in Figure 7), and at least three specimens were utilized for each biaxial loading ratio test. Strain gauges were employed to measure biaxial tensile deformation on centrally diamond-shaped thinner area of the specimen. Load versus strain curves of specimens under biaxial tensile loadings were recorded. Afterwards, the FE analysis was adopted to model the biaxial tensile stresses on centrally diamond-shaped thinner area of the specimen under biaxial tensile loadings in the previously tests. Thus, the stress versus strain curves at different loading ratios were obtained (shown in Figure 8). From Figure 8, the biaxial tensile moduli can be estimated (listed in Table 2). From Table 2, it is clear that under biaxial tensile loadings, the warp and weft moduli increase with the increasing loading ratio.

\subsection{Comparisons and discussion}

In order to validate new analytical models presented in this paper, it is necessary to compare the predictions using the new models with the experiments. From the fabric specifications and mechanical properties listed in Table 1, by using Equations (29) and (30), the biaxial tensile moduli of PWF composites are predicted (shown in Table 2). From Table 2, it is evident that maximum relative deviations of predictions for warp and weft biaxial tensile moduli from experiments are respectively $6.33 \%$ and $8.22 \%$, with an acceptable scatter. Also, the predictions of biaxial tensile moduli increase with the increasing loading ratio, namely, the proposed model has adequately and 
logically depicted the physical characteristics and the phenomenological quantitative laws in the variation of biaxial tensile moduli with changing loading ratios. Importantly, biaxial tensile moduli of PWF composites could be predicted using these models without any additional fabric level experimental investigation, i.e. only the input of basic properties of woven fabric yarns is needed to predict biaxial tensile moduli of PWF composites. As a result, it is argued that the new models presented in this paper are a valid and rational basis for biaxial tensile moduli of PWF composites.

\section{CONCLUSIONS}

The focus of this paper has been to present a novel micromechanical curved beam model for predicting the biaxial tensile moduli of PWF composites by accounting for the interaction between orthogonal interlacing yarns. New analytical solution of the model was derived to calculate biaxial tensile moduli of PWF composites by means of the minimum total complementary potential energy principle founded on micromechanics. The applicability of the models for predicting biaxial tensile moduli of PWF composites from fabric specifications and mechanical properties of constituents has been proved successfully. Reasonable correlation was achieved between the predictions and actual experimental results.

\section{ACKNOWLEDGEMENTS}

This project was supported by the National Natural Science Foundation of China (Grant No. 51375033 and 51405006).

\section{REFERENCES}

[1] Mahadik Y, Hallett SR. Effect of fabric compaction and yarn waviness on 3D woven composite 
compressive properties. Composites: Part A, 2011; 42(11): 1592-1600.

[2] Bai JB, Xiong JJ, Liu M, Man ZY. Analytical solutions for predicting tension and shear moduli of triaxial weave fabric composites. Acta Mechanica Solida Sinica, 2016; 29(1):59-77.

[3] Kuth ABH. Size-influenced mechanical isotropy of singly-plied triaxially woven fabric composites. Composites: Part A, 2014; 57(1):76-87.

[4] Bai JB, Xiong JJ, Cheng X. Tear resistance of orthogonal kevlar-PWF-reinforced TPU film. Chinese Journal of Aeronautics, 2011; 24 (1):113-118.

[5] Xiong JJ, Shenoi RA, Cheng X. A modified micromechanical curved beam analytical model to predict the tension modulus of 2D plain weave fabric composites. Composites Part B, 2009; 40(8): 776-783.

[6] Xiong JJ, Shenoi RA, Gao J. An analytical model to predict residual thermal stress in 2D orthogonal plain weave fabric composites. International Journal of Solids and Structures, 2009; 46(9):1872-1883.

[7] Bakar IAA, Kramer O, Bordas S, Rabczuk T. Optimization of elastic properties and weaving patterns of woven composites. Composite Structures, 2013; 100:575-591.

[8] Wang Y, Chen X, Young R, Kinloch I. A numerical and experimental analysis of the influence of crimp on ballistic impact response of woven fabrics. Composite Structures, 2016; 140: $44-52$.

[9] Chu TL, Ha-Minh C, Imad A. A numerical investigation of the influence of yarn mechanical and physical properties on the ballistic impact behavior of a Kevlar KM2 ${ }^{\circledR}$ woven fabric. Composites Part B, 2016; 95: 144-154.

[10] Tapie E, Guo YB, Shim VPW. Yarn mobility in woven fabrics - a computational and experimental study. International Journal of Solids and Structures, 2016; 80: 212-226. 
[11]Nilakantan G, Jr JWG. Yarn pull-out behavior of plain woven Kevlar fabrics: Effect of yarn sizing, pullout rate, and fabric pre-tension. Composite Structures, 2013; 101: 215-224.

[12]Cheng X, Xiong JJ, Bai JB. An analytical solution to predict the shear modulus of 2D plain weave fabric composites. Chinese Journal of Aeronautics, 2012; 25(4): 575-583.

[13] Cheng X, Xiong JJ. A novel analytical model for predicting the compression modulus of 2D PWF composites. Composite Structures, 2009; 88(2):296-303.

[14]Koohbor B, Ravindran S, Kidane A. Meso-scale strain localization and failure response of an orthotropic woven glassefiber reinforced composite. Composites Part B, 2015; 78:308-318.

[15]Koohbor B, Ravindran S, Kidane A. Experimental determination of Representative Volume Element (RVE) size. Optics and Lasers in Engineering, 2017; 90: 59-71.

[16] Boufaida Z, Farge L, André S, Meshaka Y. Influence of the fiber/matrix strength on the mechanical properties of a glass fiber/thermoplastic-matrix plain weave fabric composite. Composites: Part A, 2015; 75: 28-38.

[17] Scida D, Aboura Z, M.L. Benzeggagh ML, Bocherens E. A micromechanics model for 3D elasticity and failure of woven-fibre composite materials. Composites Science and Technology, 1999; 59: 505-517.

[18]Jiang Y, Tabiei A, Simitses GJ. A novel micromechanics-based approach to the derivation of constitutive equations for local/global analysis of a plain-weave fabric composite. Composites Science and Technology, 2000; 60: 1825-1833.

[19] Naik NK, Tiwari SI, Kumar RS. An analytical model for compressive strength of plain weave fabric composites. Composites Science and Technology, 2003, 63: 609-625.

[20] Wang H, Wang Z. Quantification of effects of stochastic feature parameters of yarn on elastic properties of plain-weave composite. Part 1: Theoretical modeling. Composites: Part A, 2015; 
78: 84-94.

[21] Wang H, Wang Z. Quantification of effects of stochastic feature parameters of yarn on elastic properties of plain-weave composite - Part 2: Statistical predictions vs. mechanical experiments. Composites: Part A, 2016; 84: 147-157.

[22]Karkkainen RL, Sankar BV. A direct micromechanics method for analysis of failure initiation of plain weave textile composites. Composites Science and Technology, 2006; 66: 137-150.

[23]Barbero EJ, Trovillion J, Mayugo JA, Sikkil KK. Finite element modeling of plain weave fabrics from photomicrograph measurements. Composite Structures, 2006; 73: 41-52.

[24]Bakar IAA, Kramer O, Bordas S, Rabczuk T. Optimization of elastic properties and weaving patterns of woven composites. Composite Structures, 2013; 100: 575-591.
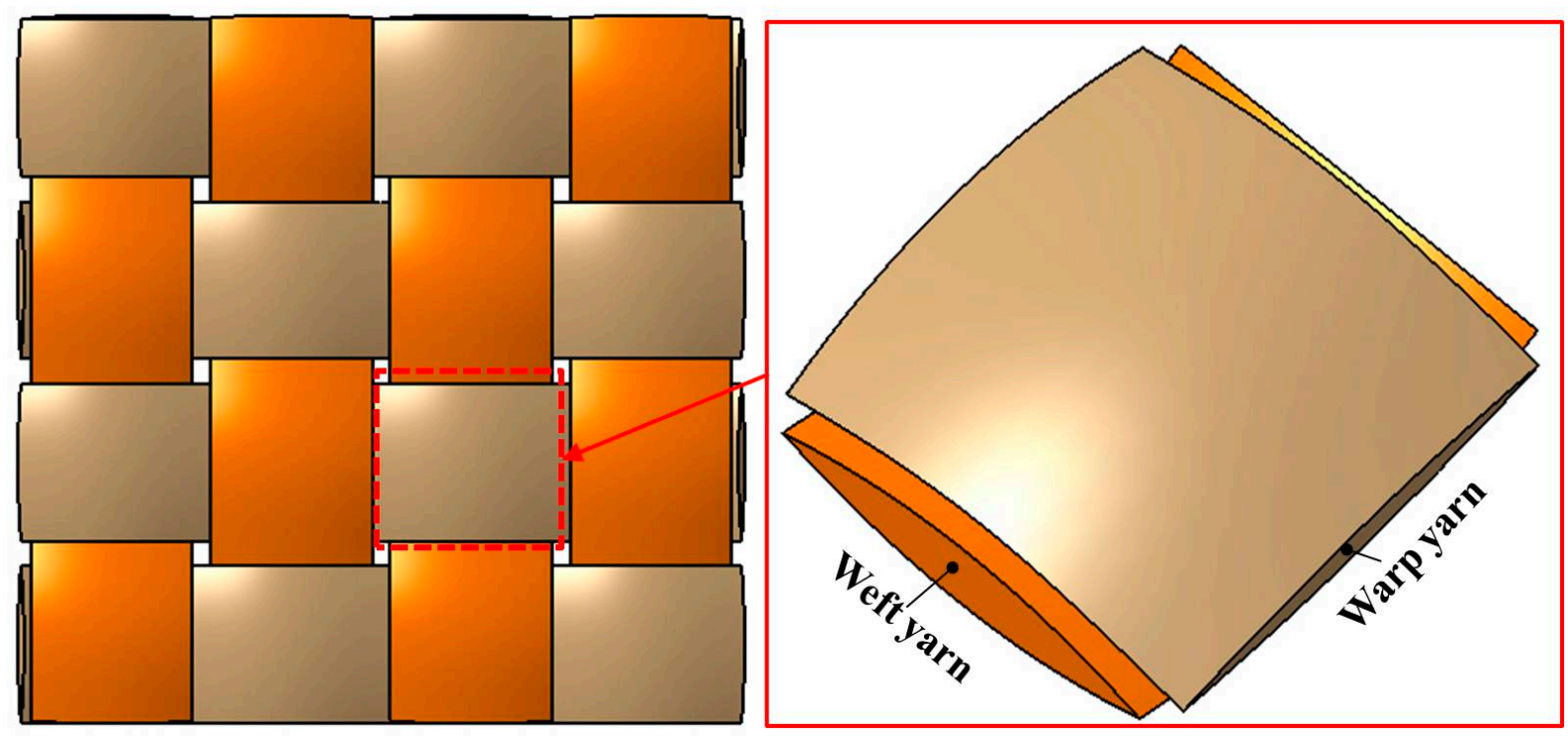

Figure 1 Unit cell of PWFs 


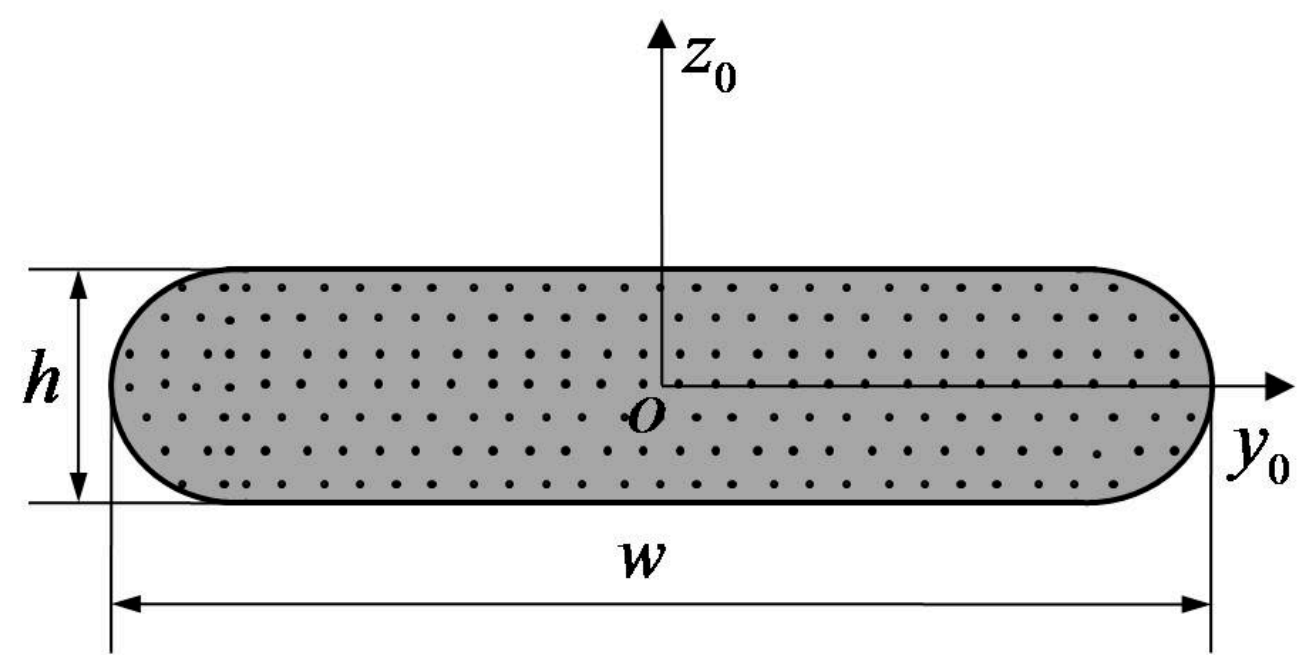

Figure 2 Local coordinate systems and idealized geometric configuration of yarns

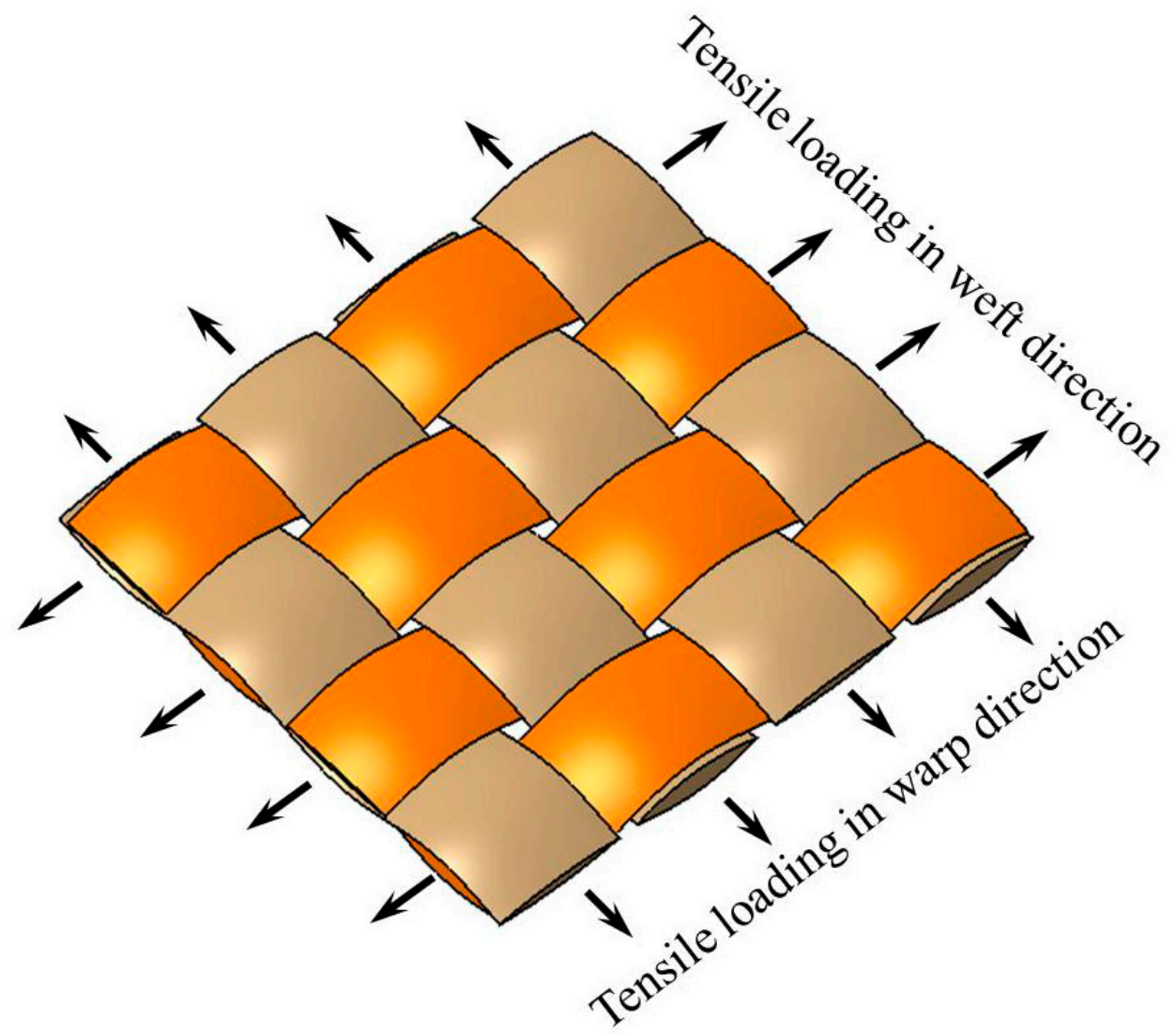

Figure 3 PWFs under biaxial tensile loadings 


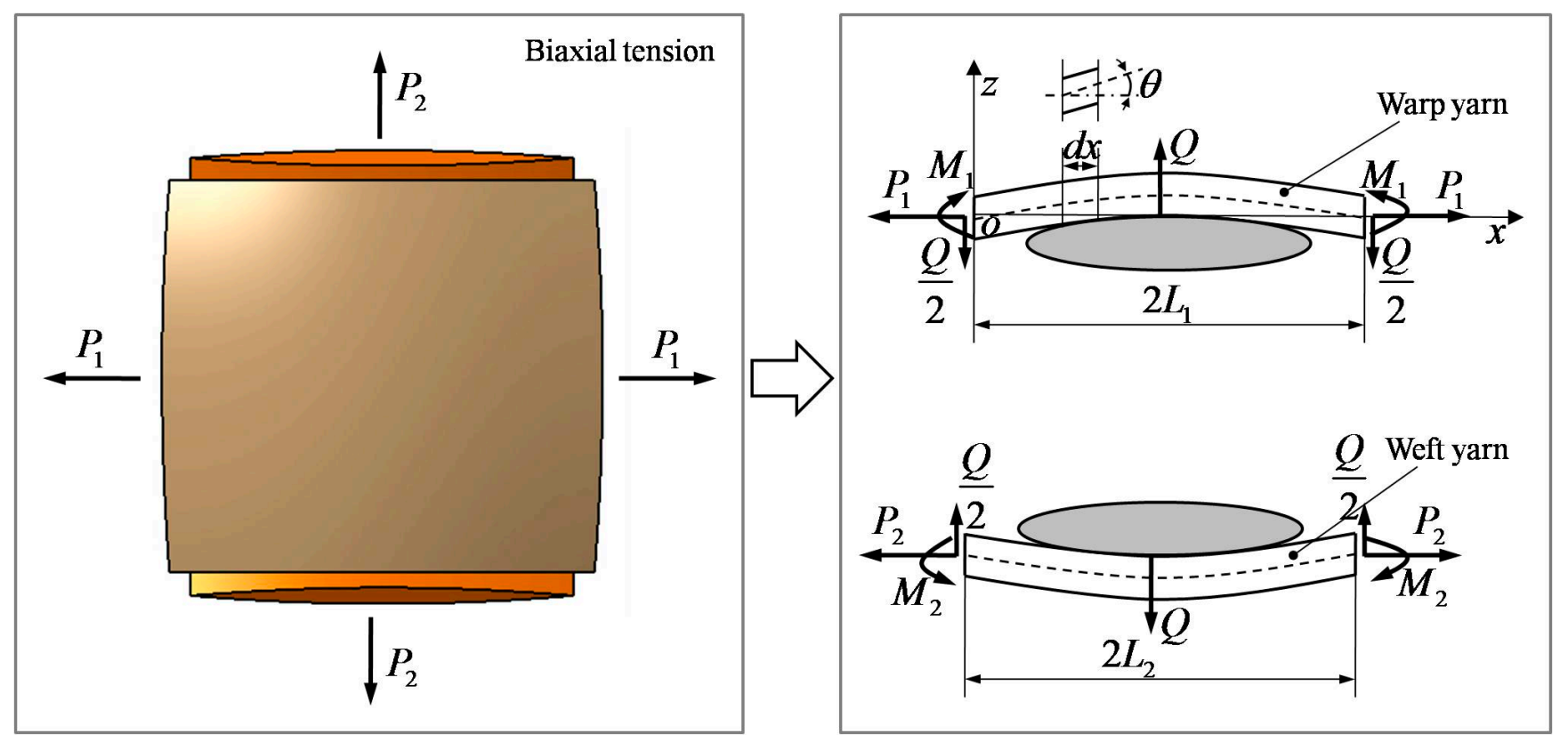

Figure 4 Internal forces and bending moments on warp and weft yarns in biaxial tensile state

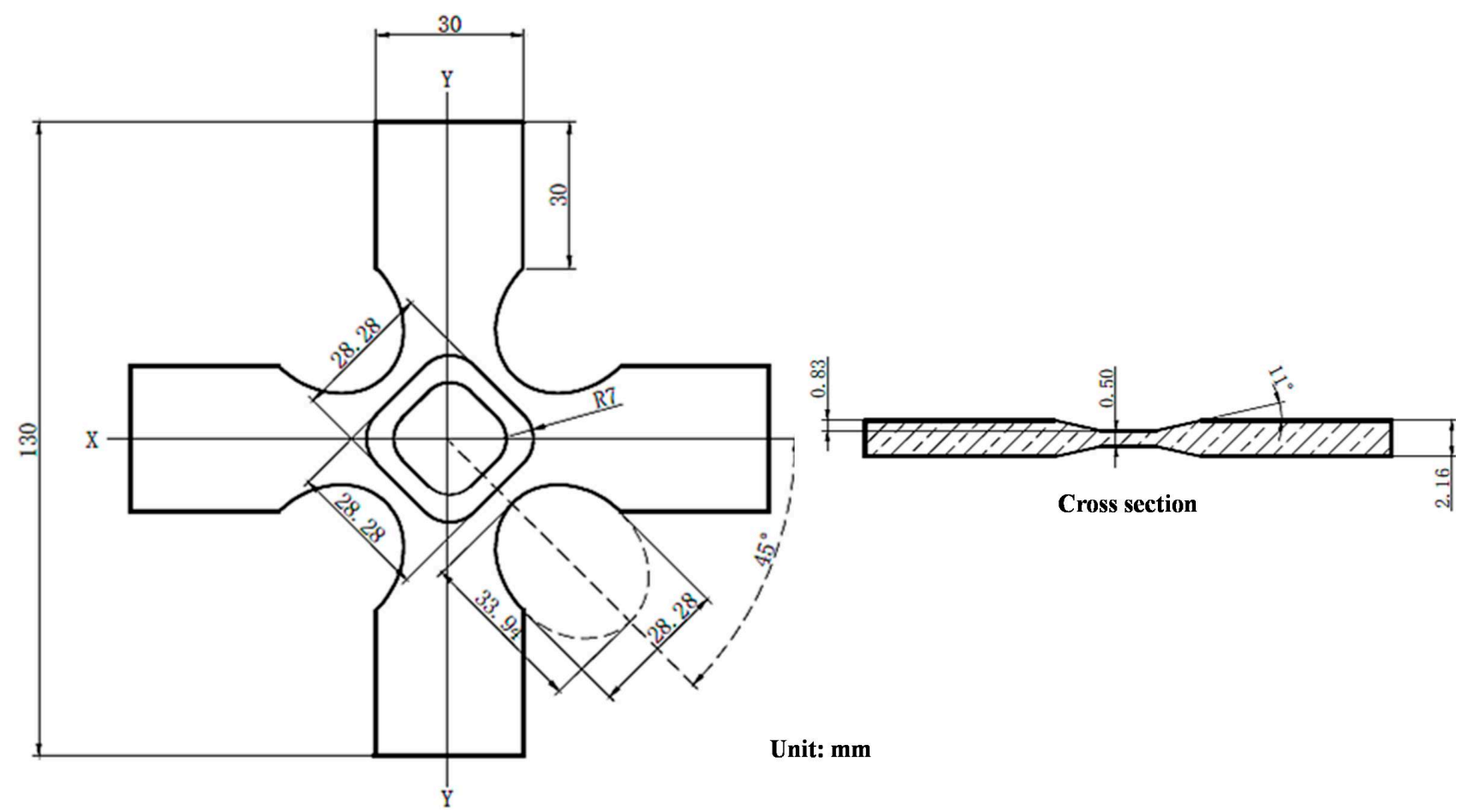

Figure 5 Geometry and dimensions of the biaxial tensile specimen 




Figure 6 Biaxial tensile test device

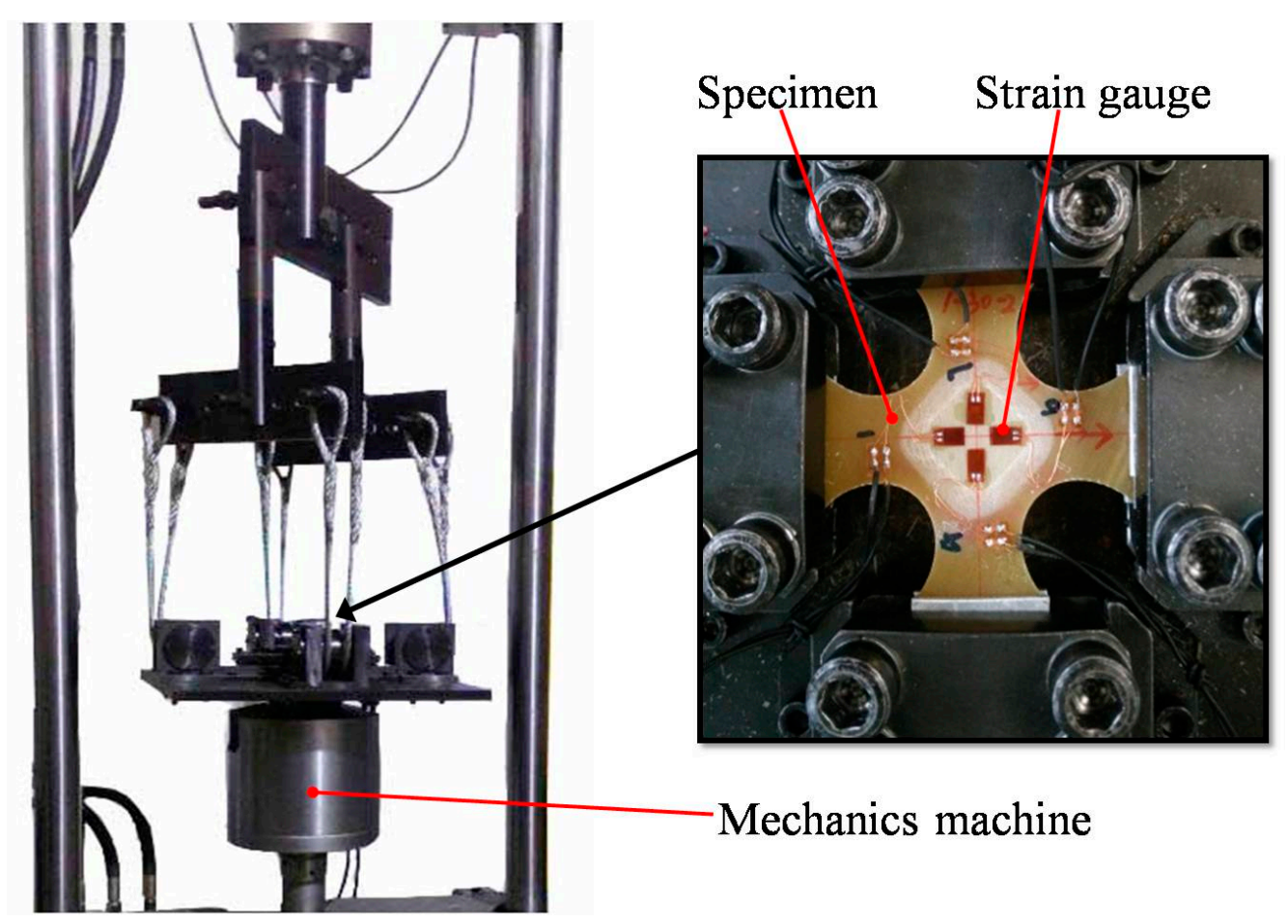

Figure 7 Biaxial tensile test of PWF composites 


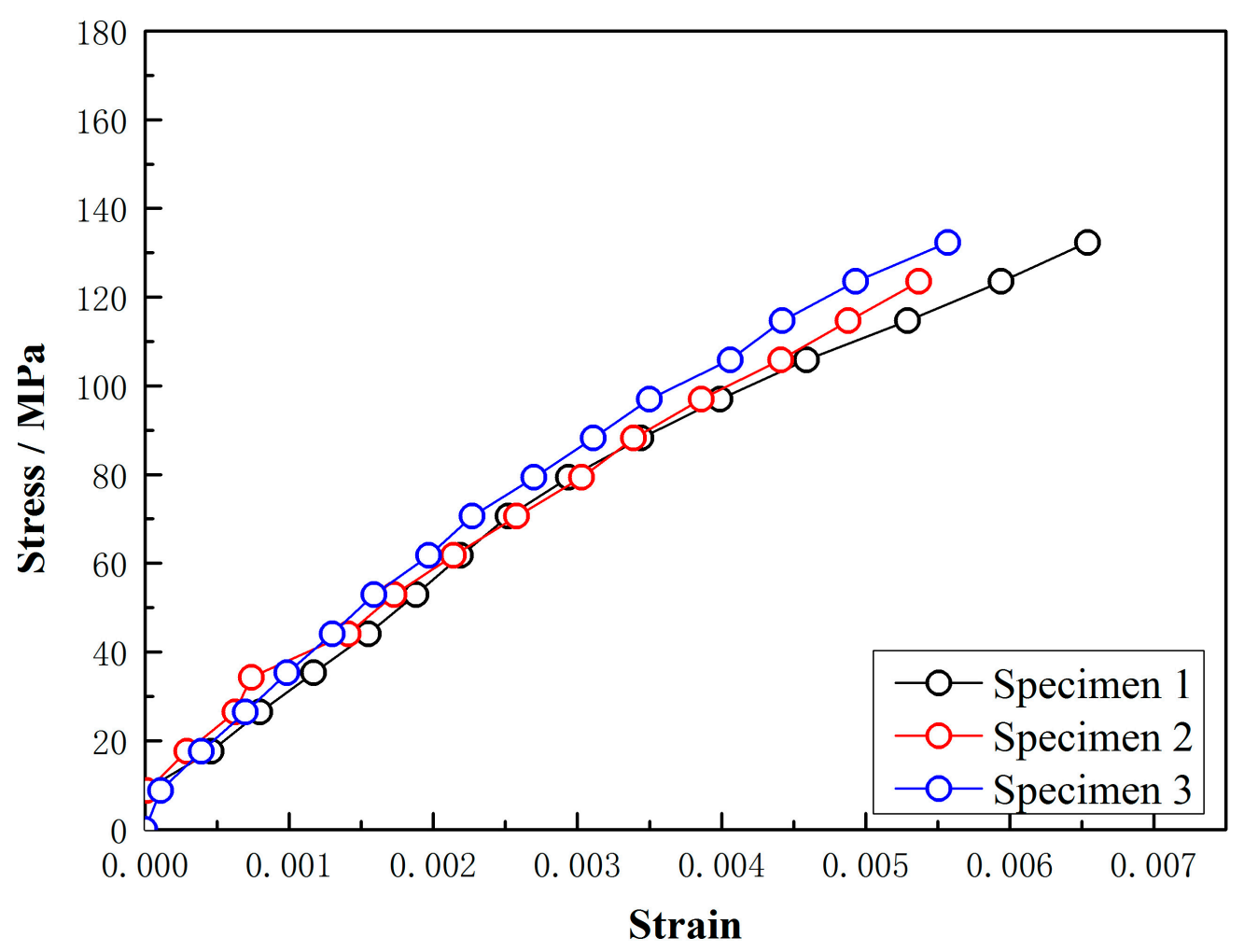

(a) Stress versus strain curves in warp direction at loading ratio $\lambda=1$

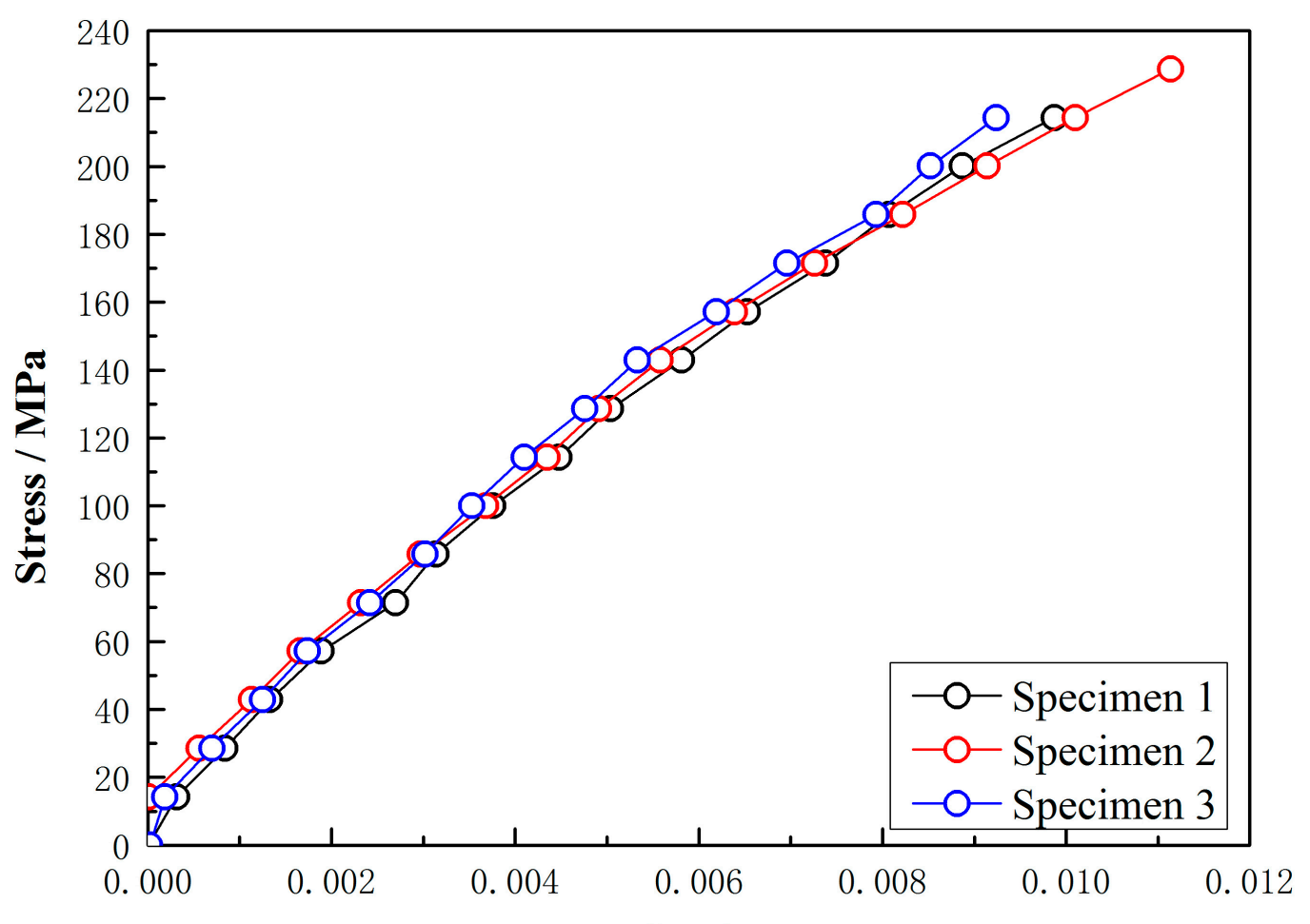

Strain

(b) Stress versus strain curves in warp direction at loading ratio $\lambda=2$ 


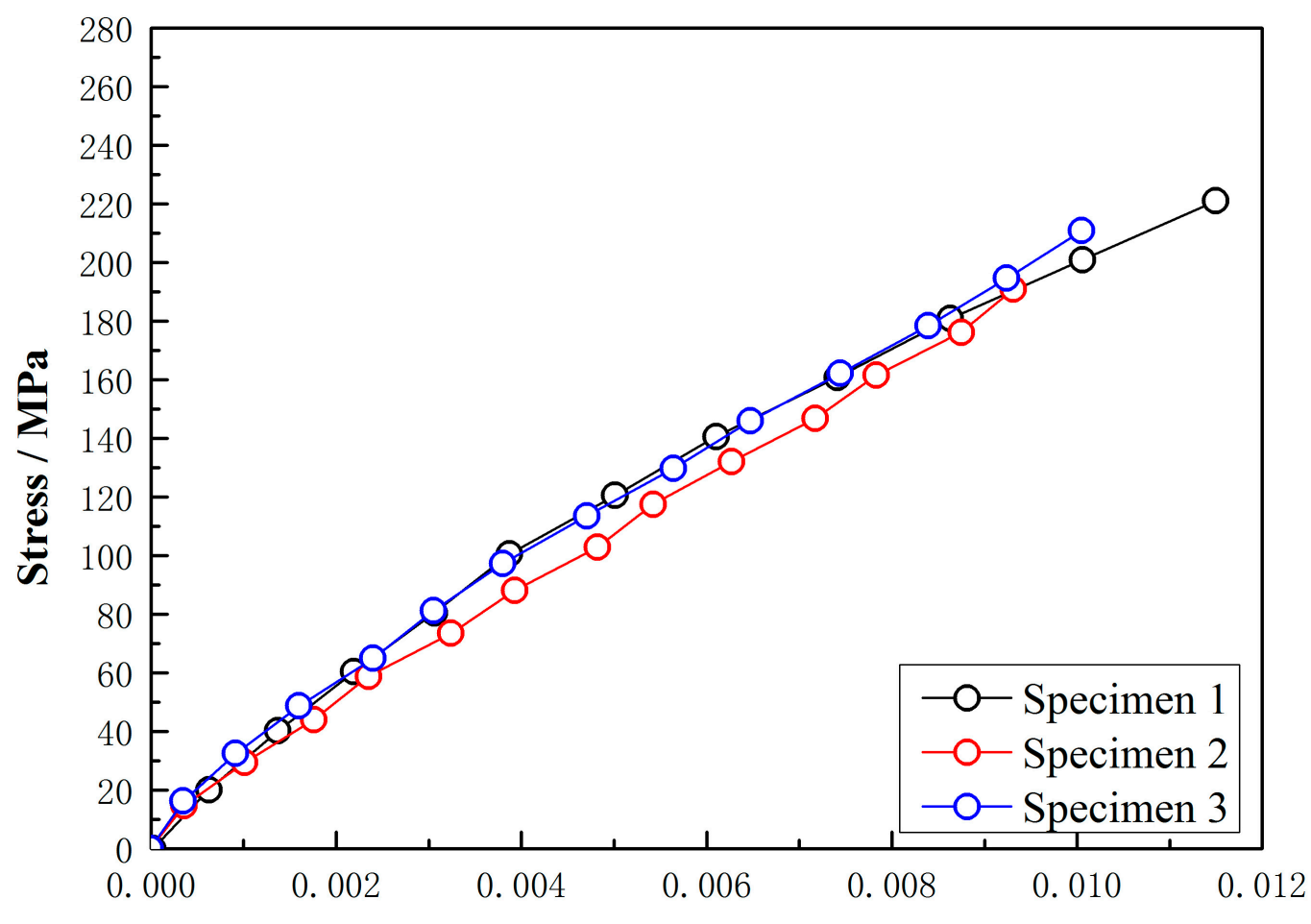

Strain

(c) Stress versus strain curves in warp direction at loading ratio $\lambda=3$

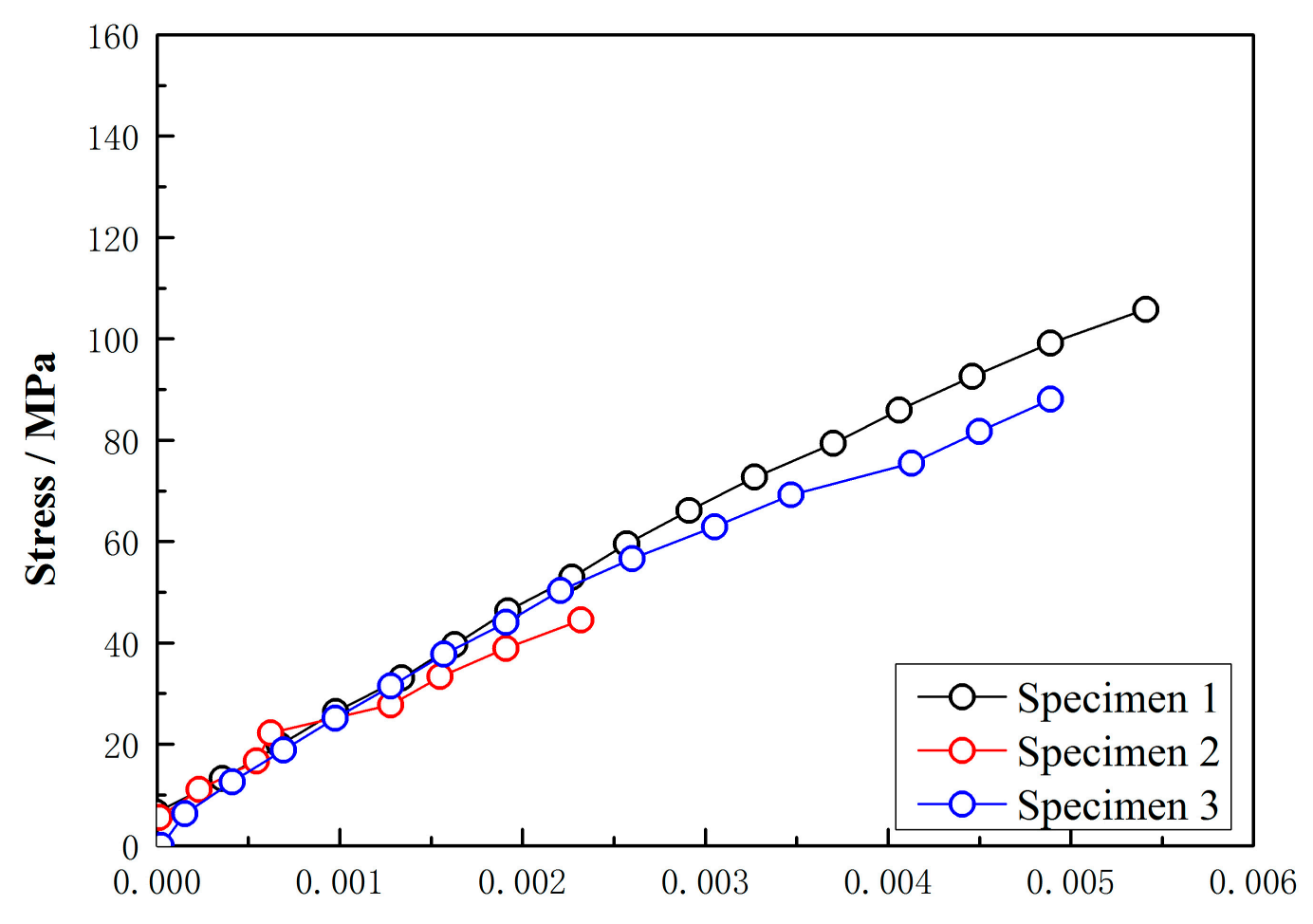

Strain

(d) Stress versus strain curves in weft direction at loading ratio $\lambda=1$ 


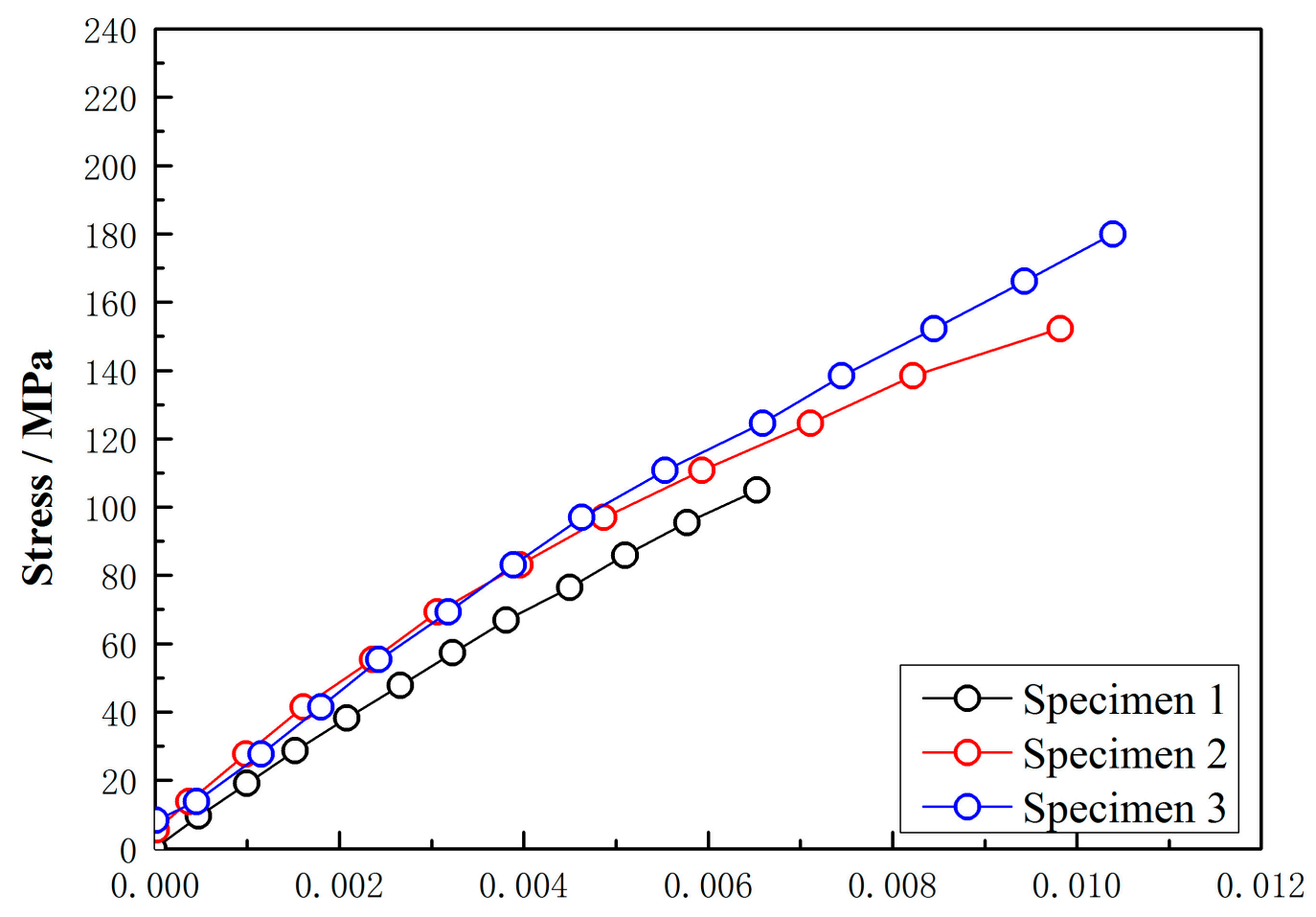

Strain

(e) Stress versus strain curves in weft direction at loading ratio $\lambda=1 / 2$



(f) Stress versus strain curves in weft direction at loading ratio $\lambda=1 / 3$

Figure 8 Experimental stress versus strain curves from biaxial tensile test of PWF composites 
Table 1 Fabric specifications and mechanical properties of EW220/5284 PWF composites

\begin{tabular}{|c|c|c|c|}
\hline$h_{1}(\mathrm{~mm})$ & 0.080 & $w_{2}(\mathrm{~mm})$ & 1.2 \\
\hline$h_{2}(\mathrm{~mm})$ & 0.067 & $H(\mathrm{~mm})$ & 0.167 \\
\hline$L_{1}(\mathrm{~mm})$ & 0.714 & $E_{f}(\mathrm{GPa})$ & 73.0 \\
\hline$L_{2}(\mathrm{~mm})$ & 0.556 & $E_{m}(\mathrm{GPa})$ & 3.4 \\
\hline$w_{1}(\mathrm{~mm})$ & 1.0 & $V_{f 1}$ & 0.55 \\
\hline
\end{tabular}

Table 2 Biaxial tensile moduli of EW220/5284 PWF composites

\begin{tabular}{|c|c|c|c|c|c|c|c|c|}
\hline \multirow{2}{*}{ Specimen No. } & \multicolumn{4}{|c|}{ Warp moduli (GPa) } & \multicolumn{4}{c|}{ Weft moduli (GPa) } \\
\cline { 2 - 9 } & $\lambda=1$ & $\lambda=2$ & $\lambda=3$ & $\lambda=\infty$ & $\lambda=1$ & $\lambda=1 / 2$ & $\lambda=1 / 3$ & $\lambda=0$ \\
\hline 1 & 19.22 & 21.55 & 18.96 & 18.37 & 18.22 & 16.11 & 15.41 & 14.12 \\
\hline 2 & 21.00 & 19.39 & 19.61 & 20.23 & 16.20 & 15.17 & 15.86 & 13.62 \\
\hline 3 & 23.53 & 20.70 & 20.04 & 19.24 & 17.41 & 16.72 & 16.11 & 14.70 \\
\hline Mean values of & 21.25 & 20.55 & 19.54 & 19.28 & 17.28 & 16.00 & 15.79 & 14.14 \\
\hline Experiments & & & & & & & & \\
\hline Predictions & 20.31 & 19.25 & 18.92 & 18.30 & 15.86 & 14.83 & 14.52 & 13.94 \\
\hline Relative deviation & $4.42 \%$ & $6.33 \%$ & $3.17 \%$ & $5.08 \%$ & $8.22 \%$ & $7.31 \%$ & $8.04 \%$ & $1.41 \%$ \\
\hline
\end{tabular}

\section{APPENDIX A Definitions for Transformation Variables $C_{i}$}

$$
\begin{gathered}
C_{1}=\frac{1}{E I_{1}} \int_{0}^{L_{1}} \sqrt{1+\left(\frac{\pi h_{1}}{4 L_{1}} \cos \frac{\pi x}{2 L_{1}}\right)^{2}} d x \\
C_{2}=\frac{1}{E I_{1}} \int_{0}^{L_{1}}\left(\frac{h_{1}}{2} \sin \frac{\pi x}{2 L_{1}}\right)^{2} \sqrt{1+\left(\frac{\pi h_{1}}{4 L_{1}} \cos \frac{\pi x}{2 L_{1}}\right)^{2}} d x
\end{gathered}
$$




$$
\begin{aligned}
& C_{3}=\frac{1}{4 E I_{1}} \int_{0}^{L_{1}} x^{2} \sqrt{1+\left(\frac{\pi h_{1}}{4 L_{1}} \cos \frac{\pi x}{2 L_{1}}\right)^{2}} d x \\
& C_{4}=\frac{1}{E I_{1}} \int_{0}^{L_{1}}\left(h_{1} \sin \frac{\pi x}{2 L_{1}}\right) \sqrt{1+\left(\frac{\pi h_{1}}{4 L_{1}} \cos \frac{\pi x}{2 L_{1}}\right)^{2}} d x \\
& C_{5}=\frac{-1}{2 E I_{1}} \int_{0}^{L_{1}} x\left(h_{1} \sin \frac{\pi x}{2 L_{1}}\right) \sqrt{1+\left(\frac{\pi h_{1}}{4 L_{1}} \cos \frac{\pi x}{2 L_{1}}\right)^{2}} d x \\
& C_{6}=\frac{-1}{E I_{1}} \int_{0}^{L_{1}} x \sqrt{1+\left(\frac{\pi h_{1}}{4 L_{1}} \cos \frac{\pi x}{2 L_{1}}\right)^{2}} d x \\
& C_{7}=\frac{1}{E A_{1}} \int_{0}^{L_{1}}\left[\sqrt{1+\left(\frac{\pi h_{1}}{4 L_{1}} \cos \frac{\pi x}{2 L_{1}}\right)^{2}}\right]^{-1} d x \\
& C_{8}=\frac{1}{4 E A_{1}} \int_{0}^{L_{1}}\left(\frac{\pi h_{1}}{4 L_{1}} \cos \frac{\pi x}{2 L_{1}}\right)^{2}\left[\sqrt{1+\left(\frac{\pi h_{1}}{4 L_{1}} \cos \frac{\pi x}{2 L_{1}}\right)^{2}}\right]^{-1} d x \\
& C_{9}=\frac{1}{E A_{1}} \int_{0}^{L_{1}}\left(\frac{\pi h_{1}}{4 L_{1}} \cos \frac{\pi x}{2 L_{1}}\right)\left[\sqrt{1+\left(\frac{\pi h_{1}}{4 L_{1}} \cos \frac{\pi x}{2 L_{1}}\right)^{2}}\right]^{-1} d x \\
& C_{10}=\frac{1}{E I_{2}} \int_{0}^{L_{2}} \sqrt{1+\left(\frac{\pi h_{2}}{4 L_{2}} \cos \frac{\pi x}{2 L_{2}}\right)^{2}} d x \\
& C_{11}=\frac{1}{E I_{2}} \int_{0}^{L_{2}}\left(\frac{h_{2}}{2} \sin \frac{\pi x}{2 L_{2}}\right)^{2} \sqrt{1+\left(\frac{\pi h_{2}}{4 L_{2}} \cos \frac{\pi x}{2 L_{2}}\right)^{2}} d x \\
& C_{12}=\frac{1}{4 E I_{2}} \int_{0}^{L_{2}} x^{2} \sqrt{1+\left(\frac{\pi h_{2}}{4 L_{2}} \cos \frac{\pi x}{2 L_{2}}\right)^{2}} d x \\
& C_{13}=\frac{1}{E I_{2}} \int_{0}^{L_{2}}\left(h_{2} \sin \frac{\pi x}{2 L_{2}}\right) \sqrt{1+\left(\frac{\pi h_{2}}{4 L_{2}} \cos \frac{\pi x}{2 L_{2}}\right)^{2}} d x \\
& C_{14}=\frac{-1}{2 E I_{2}} \int_{0}^{L_{2}} x\left(h_{2} \sin \frac{\pi x}{2 L_{2}}\right) \sqrt{1+\left(\frac{\pi h_{2}}{4 L_{2}} \cos \frac{\pi x}{2 L_{2}}\right)^{2}} d x \\
& C_{15}=\frac{-1}{E I_{2}} \int_{0}^{L_{2}} x \sqrt{1+\left(\frac{\pi h_{2}}{4 L_{2}} \cos \frac{\pi x}{2 L_{2}}\right)^{2}} d x \\
& C_{16}=\frac{1}{E A_{2}} \int_{0}^{L_{2}}\left[\sqrt{1+\left(\frac{\pi h_{2}}{4 L_{2}} \cos \frac{\pi x}{2 L_{2}}\right)^{2}}\right]^{-1} d x
\end{aligned}
$$




$$
\begin{gathered}
C_{17}=\frac{1}{4 E A_{2}} \int_{0}^{L_{2}}\left(\frac{\pi h_{2}}{4 L_{2}} \cos \frac{\pi x}{2 L_{2}}\right)^{2}\left[\sqrt{1+\left(\frac{\pi h_{2}}{4 L_{2}} \cos \frac{\pi x}{2 L_{2}}\right)^{2}}\right]^{-1} d x \\
C_{18}=\frac{1}{E A_{2}} \int_{0}^{L_{2}}\left(\frac{\pi h_{2}}{4 L_{2}} \cos \frac{\pi x}{2 L_{2}}\right)\left[\sqrt{1+\left(\frac{\pi h_{2}}{4 L_{2}} \cos \frac{\pi x}{2 L_{2}}\right)^{2}}\right]^{-1} d x
\end{gathered}
$$

\section{APPENDIX B Definitions for Transformation Variables $D_{i}$}

$$
D_{1}=\frac{\left|\begin{array}{ccc}
-C_{4} & 0 & C_{6} \\
-\frac{C_{13}}{\lambda} & 2 C_{10} & C_{15} \\
-\left[\left(C_{5}+C_{9}\right)+\frac{1}{\lambda}\left(C_{14}+C_{18}\right)\right] & C_{15} & 2\left(C_{3}+C_{8}+C_{12}+C_{17}\right)
\end{array}\right|}{\left|\begin{array}{ccc}
2 C_{1} & 0 & C_{6} \\
0 & 2 C_{10} & C_{15} \\
C_{6} & C_{15} & 2\left(C_{3}+C_{8}+C_{12}+C_{17}\right)
\end{array}\right|}
$$

$$
D_{2}=\frac{\left|\begin{array}{ccc}
2 C_{1} & -C_{4} & C_{6} \\
0 & -\frac{C_{13}}{\lambda} & C_{15} \\
C_{6} & -\left[\left(C_{5}+C_{9}\right)+\frac{1}{\lambda}\left(C_{14}+C_{18}\right)\right] & 2\left(C_{3}+C_{8}+C_{12}+C_{17}\right)
\end{array}\right|}{\left|\begin{array}{ccc}
2 C_{1} & 0 & C_{6} \\
0 & 2 C_{10} & C_{15} \\
C_{6} & C_{15} & 2\left(C_{3}+C_{8}+C_{12}+C_{17}\right)
\end{array}\right|}
$$

$$
D_{3}=\frac{\left|\begin{array}{ccc}
2 C_{1} & 0 & -C_{4} \\
0 & 2 C_{10} & -\frac{C_{13}}{\lambda} \\
C_{6} & C_{15} & -\left[\left(C_{5}+C_{9}\right)+\frac{1}{\lambda}\left(C_{14}+C_{18}\right)\right]
\end{array}\right|}{\left|\begin{array}{ccc}
2 C_{1} & 0 & C_{6} \\
0 & 2 C_{10} & C_{15} \\
C_{6} & C_{15} & 2\left(C_{3}+C_{8}+C_{12}+C_{17}\right)
\end{array}\right|}
$$

